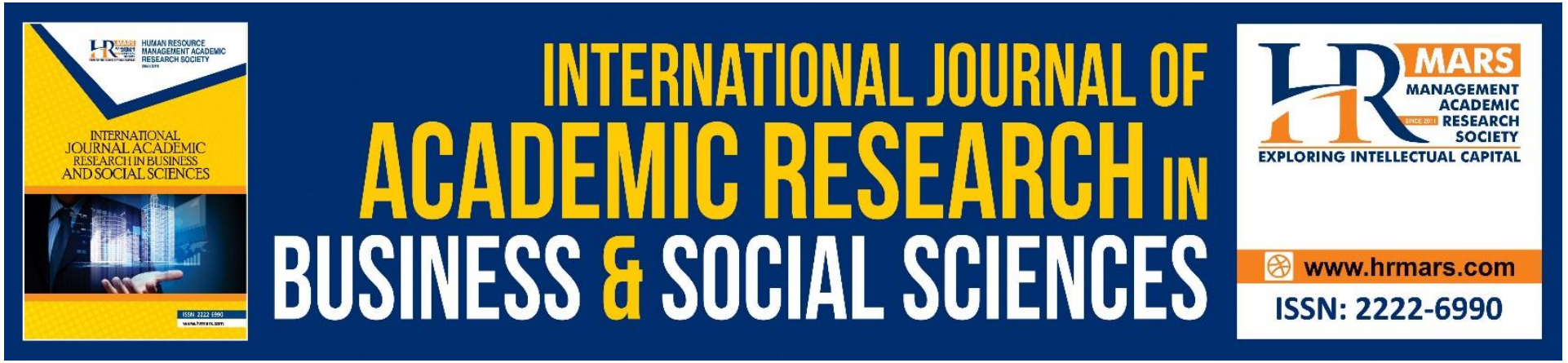

\title{
Critical Success Factors of Lean Six Sigma in Higher Education Institutions
}

\author{
Tai Jia Xin, Tan Owee Kowang, Teo Pei Kian
}

To Link this Article: http://dx.doi.org/10.6007/IJARBSS/v11-i7/10435

DOI:10.6007/IJARBSS/v11-i7/10435

Received: 14 May 2021, Revised: 18 June 2021, Accepted: 30 June 2021

Published Online: 06 July 2021

In-Text Citation: (Xin et al., 2021)

To Cite this Article: Xin, T. J., Kowang, T. O., \& Kian, T. P. (2021). Critical Success Factors of Lean Six Sigma in Higher Education Institutions. International Journal of Academic Research in Business and Social Sciences, 11(7), 220-229.

\section{Copyright: (c) 2021 The Author(s)}

Published by Human Resource Management Academic Research Society (www.hrmars.com)

This article is published under the Creative Commons Attribution (CC BY 4.0) license. Anyone may reproduce, distribute, translate and create derivative works of this article (for both commercial and non-commercial purposes), subject to full attribution to the original publication and authors. The full terms of this license may be seen at: http://creativecommons.org/licences/by/4.0/legalcode

Vol. 11, No. 7, 2021, Pg. 220 - 229

Full Terms \& Conditions of access and use can be found at http://hrmars.com/index.php/pages/detail/publication-ethics 


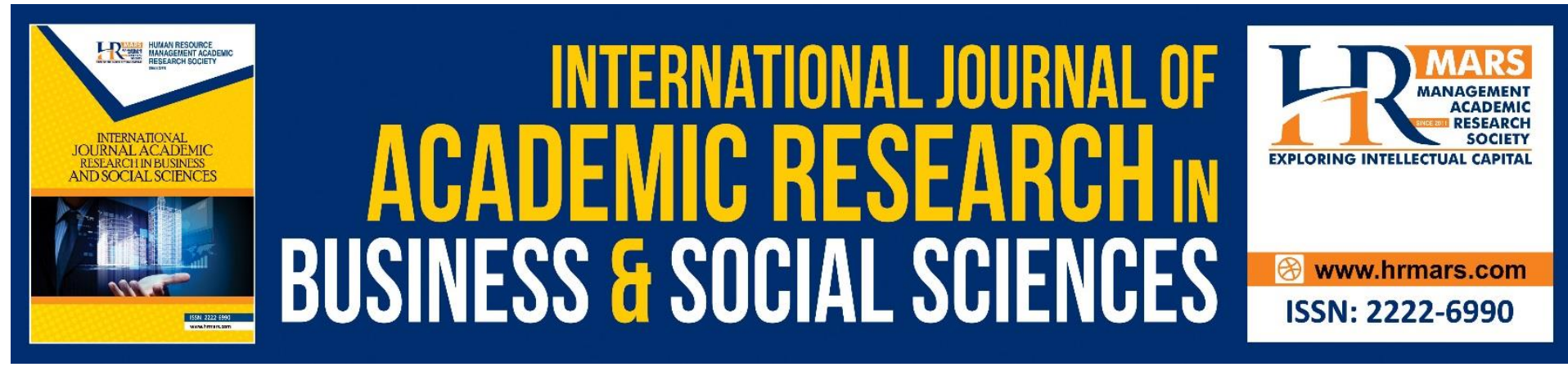

\title{
Critical Success Factors of Lean Six Sigma in Higher Education Institutions
}

\author{
Tai Jia Xin, Tan Owee Kowang, Teo Pei Kian \\ ${ }^{1}$ Azman Hashim International Business School, Universiti Teknologi Malaysia, Johor, \\ Malaysia, ${ }^{2}$ Faculty of Art and Design, Southern University College, Johor, Malaysia \\ Email: oktan@utm.my
}

\begin{abstract}
In this globalization era, the competition in industries becoming more vigorous as organizations are under constant pressure to outperform each other. Similarly in the educational sector, where Higher Education Institutions (HEIs) facing intense competition. In order to stay competitive and sustainable, continuous improvement tools are highly required by these organizations. Lean Six Sigma (LSS) is one of the powerful continuous improvement tools to enhance HEls' competitive advantages and performance. In order to improve the successful rate of implementation, this paper aimed to identify and reviewed on previous study regarding to the Critical Success Factors (CSFs) of LSS. Based on the findings, it can be concluded that all CSFs are relevant in the context of HEls, and management plays an important role in all CSFs of LSS. However, the involvement of employees serves as the support and also vital for the successful of LSS implementation as employees are the fundamental of HEls and decides the accomplishment of task and performance of HEls. Management should take the initiative to stimulate the employees, and with these CSFs serve as guidelines of LSS, HEls can adapt LSS to improve its operation and services.
\end{abstract}

Keywords: Critical Success Factors, Lean Six Sigma, Higher Education Institutions

\section{Introduction}

In recent years, the competition in education sector, especially among the Higher Education Institutions (HEIs), has become vigorous due to the effect of globalization. According to the Malaysia Educational Blueprint 2015-2025, there are 70 private universities, 34 university colleges and 410 colleges in Malaysia (Ministry of Education, 2013). Out of these HEls, some of them are foreign HEls which have high ranking in their local countries. These statistics show that Malaysia HEls are facing intensive competition and strive to outperform each other in the sector in order to survive under high pressure. Therefore, continuous improvement tools have becoming an essential part for HEls in order to stay competitive.

Lean Six Sigma (LSS), which results from the integration of Lean and Six Sigma, is well recognized as a powerful continuous improvement tool. The two components, Lean and Six Sigma are focusing on reducing waste by eliminating non-value-added activities (Pepper and Spedding, 2010) and improving quality by reduce defects and variations (Mehrjerdi, 2011) 
respectively. By combining these two effective tools, LSS were widely used to improve efficiency and effectiveness of organization, enhance customer satisfaction, at the same time, increase the bottom-line result (Antony, et al., 2012; Antony, 2014). Hess and Benjamin further explained the advantages of LSS where it serves as a catalyst for HEls to identify customers' needs effectively and act as an agent for cultural change in HEls.

Despite the advantages bring by LSS, the high failure rate resulting the implementation of LSS in HEls is very rare. This might be due to the lack of framework and guidelines of LSS implementation, especially in terms of HEls. According to Vijaya (2016), the research regarding to the implementation of LSS in educational field is in a very nascent stage. Furthermore, some of the organizations sent their employees to the LSS training but the outcomes are not as good as expected. This might be due to the organizations do not have true understanding on LSS and the employees who being sent to the training do not have chances to practice LSS in job setting (Kulach, 2013). Besides, Antony et al. (2012) and ElHomsi and Slutsky (2010) also suggested that high failure rate might be due to lack of management commitment in LSS, and inappropriate leadership while implementing LSS.

In order to increase the successful rate of LSS implementation, there are several researchers who studied on the critical success factors (CSFs) of implementing LSS. Several CSFs were investigated by previous researchers including management commitment, training, cultural change, linking LSS to HR rewards, project prioritization and etc. (Antony and Banuelas, 2002; Kwak and Anbari, 2006; Jayaraman and Teo, 2010; Brun, 2011; Lande et al., 2016; Ali, Choong and Jayaraman, 2016; Singh and Singh, 2020). These CSFs are mainly focusing on the manufacturing industries. In education context, the relationship of CSFs and performance of HEls such as operational performance need to be examined to make sure the relevancy of the CSFs.

\section{Literature Review}

This study will start with the discussion on Lean, Six Sigma, Lean Six Sigma, followed by Critical Success Factors (CSFs) of Lean Six Sigma. The critical role of these CSFs is discussed in the following section.

\section{Lean}

Lean is the concept developed by Taiichi Ohno, the head of Toyota's manufacturing plant for its Toyota Production System (TPS). The definition of Lean was unclear even some of the authors trying to define this term due to different direction of defining by different authors. For example, Pettersen (2009) defined Lean based on the tools and effort done by the organizations while Bhasin and Burcher (2006) defined it based on the Lean Thinking which is the philosophical characteristic of Lean. Some authors suggested that the definition of Lean should include both. To sum up the definitions, Professor James Womack, Daniel Jones, and Daniel Rosa defines Lean as a set of thinking and a set of principles that eliminate non-valueadded activities and waste to improve organization effectiveness and efficiency (Melovic, et al., 2016).

According to Lean, there are seven groups of wasted being identified by Taiichi Ohno, which are overproduction, waiting time, transport, excessive processing, stock of raw material and semi-finishing goods, unnecessarily movement of labour, equipment, and material and 
frequent errors (Melovic, et al., 2016). Lean helps to reduce or even eliminate these seven groups of wastes to enhance the operation of organization. Taj and Berro (2005) has revealed that large manufacturing plants has wasted $70 \%$ resources during the production and only $10 \%$ of them are value-added. In other words, $60 \%$ of these resources are non-value-added. According to Bhasin and Burcher (2006), $40 \%$ of the wastes can be eliminates through implementation of Lean.

\section{Six Sigma}

Six Sigma was developed by Dr. Mike Harry and the first company implemented Six Sigma methodologies, Motorola, has saved more than 15 billions over the years. In Greek alphabet, sigma was used to identify variables and the higher the sigma quality level, the lower the defect rate. With the implementation of Six sigma, organizations is expected to save cost from the reduction of variations and defects (Mehrjerdi, 2011). Anthony (2014) defined Six Sigma as the breakthrough in business strategy to evaluate process and improve quality of process through a set of structured tools and statistical measurement.

In current practice, there are two methods of Six Sigma being used in the industry, which are DMAIC (Define, Measure, Analyse, Improve and Control) and DMADV (Define, Measure, Analyse, Design and Verify). Usually DMAIC is used to improve the existing products or process while DMADV is used in the nascent stage of development of new products or services. Traditionally, Six Sigma approach is used in the manufacturing process. The success in manufacturing result in the application of Six Sigma in service industries (Bisgaard, et al., 2002).

\section{Lean Six Sigma}

The integration of Lean and Six Sigma result in the development of Lean Six Sigma (LSS). It is a concept to make work faster (Lean) and make work faster (Six Sigma) (George, et al. 2004). Snee (2010) has defined LSS as "a commercial approach which enhancing the process performance and subsequently improve customers' satisfaction and enhancing bottom line result".

There are several researchers suggested that LSS can be an excellent continuous improvement tool to minimize waste and reduce process variations (Furterer and Elshennawy, 2005; Jing, 2009; Anthony et al., 2003). It was suggested that by merging the Lean and Six Sigma allows these two methods to complement each other shortcomings and exploit on each other benefits. Besides, there are no contradiction of practice among these two methods, resulting in pairing of these two methods easy to implement and creating effective results.

In HEls, the concept of LSS is very new to the practitioners, and there are little research regarding to LSS in education. There are seven challenges need to be well aware while transferring this LSS from manufacturing to education industry (Vijaya, 2016). These challenges includes the market perspective, customer definition, defect detection, unevenness, measurement system, inseparability and people perspective. Firstly, the market perspective refers to the argument of the existence of market in education sector. Customer definition also more ambiguous in education as some researchers define customer in education as student (Mergen, et al., 2000) while some argue that employees are considered 
as the main customer of education (Kanji, et al. 1999). This is challenging in fulfilling the customers' needs as different customer group have different needs and wants. Unlike manufacturing, since education is more on selling on services and knowledges, there are difficulties in the defect detection (George, 2003). Unevenness meaning the services and knowledges sold by education are not able to be reproduced exactly since teaching staffs have different style of teaching, different contents and etc. The measurement system in education is also harder and only some indicators can be used to measure the education performance. Besides, education is inseparable and need to be carried out simultaneously, making the education more complex than manufacturing. Lastly, people challenge in the education meaning that the people are the main asset in this sector and sometimes people mind are unpredictable and may resist to change in some circumstances.

Despite the challenges of LSS implementation in education, many of the researchers found that LSS is applicable in education and Anthony (2014) even suggested that LSS could be used as the improvement tool in education to enhance students' satisfaction, reduce hidden costs and improve the culture of HEls to enhance the performance of the HEls.

\section{The Critical Success Factor (CSFs) in implementing Lean Six Sigma}

Critical Success Factors were those relatively small numbers of truly important matters where a particular industry should focus her attention in order to achieve success. Therefore, Critical Success Factors are important in providing a guideline for practitioners to aim in these aspect to increase the success rate of LSS implementation. There are five main CSFs will be discussed in the following section, which are management commitment, training, cultural change, project selection and prioritization and lastly linking LSS to human resource (HR) rewards.

\section{Management Commitment}

Management refers to those group of people have the power in decision making in an organization. Aij, et al. (2013) and Maijala, et al. (2018) mentioned that management should provide manpower commitment as well as financial aids to the employees in order to have effective implementation of improvement programs. In LSS implementation, management act as a role of motivating the employees to become active in LSS activities. For instance, managers should be participative in relevant program to serve as a role model to the employees.

Besides, management commitment can be seem in creating a continuous improvement practice in the organization. Such practice may include high open-mindedness and acceptance level culture towards the employees. By having these kind of practice, management could receive innovative ideas as subordinates are encouraged to provide their ideas and point of view in the operation of organization. Poksinka et al. (2013) suggested that this kind of culture which acknowledge subordinates' efforts, ideas and initiatives will result in improvement.

In HEls, management should be always aware that by implementing LSS, organizational change is inevitable as it will ultimately leads to improvement as whole. Therefore, management such as Chancellor, Deans and Directors of academic departments and administrative departments should provide concerted commitment, as mentioned by Pande and Holpp (2002). The management team who encourage ideas, opinions and wiling to change are more likely to succeed in the LSS implementation. As in the research of Quinn et 
al., (2009) suggested that reluctant to change is one of the factors hindering the implementation of improvement programs. This is especially important in HEls as most of the employees are highly educated and may resist to change due to own ideas and strong believe in themselves.

\section{Training}

Training could be identified as one of the important CSFs in implementing LSS (Antony and Banuelas, 2002; Kwak and Anbari, 2006; Jayaraman and Teo, 2010; Brun, 2011; Lande et al., 2016; Ali, Choong and Jayaraman, 2016; Singh and Singh, 2020). Although the management could be vital in deciding the directions of organization, employees as the base of the organization also crucial in accomplishing tasks and deciding the performance of organization (Rodriguez and Walters, 2017). Hence organization training should be enforced from time to time, ensuring the employees are competitive and well aware of the current trend to stay sustainable in the industry.

In LSS implementation, or in any continuous improvement programs, it is undeniable that training plays an critical role in enhancing the success rate of the implementation as without knowledge, it is not likely to be successful in continuous improvement program. LSS have formed its own training, which comprised of a belt system. In this belt system, the level of practitioner or trainee are categorized into different level, starting from Green Belt, Black Belt to Master Black Belt. Although the training is readily for LSS, ineffective training may further hinder the implementation of LSS as some training may only focus on the technique but not telling the impact on business (Godfrey, 2005; Keim, 2011). It may cause the trainee to become loss interest in LSS due to wrong perceptions.

\section{Cultural Change}

Cultural Change is a vital part in implementing LSS. Culture is defined by Kotter and Heskett (1992) as the collective of belief, norms, values and behaviour of a group of people in an organization. Due to these belief, norms, values and behaviour, these people are differentiated from others (Geert, et al., 2010). LSS is a change process, where also changing the people belief, norms, values and behaviour in the organization to achieve improvement. Therefore, implementation of LSS will definitely need of cultural change to ensure the organization moving from the current stage to the desired stage.

There are researchers mentioned that creating a culture of learning would be essential in implementing LSS (Aij and Teunissen, 2017). Learning culture is important in terms of overall improvement in the skills set and competencies of the employees. With a learning culture, employees are willing to explore new skills and new knowledge, which is beneficial to the organization. Goodridge et al. (2015) also mentioned that superior should create an environment of learning to employees by regard mistake as opportunities to encourage learning. Besides, Aij and Teunissen (2017) also mentioned that superior can further enhance the learning environment by challenging the subordinates and evaluate their performance as well as provide managerial versatility.

Similarly, in HEls, creating a learning environment should be familiar in education sector to students. However, it was always being neglect about the staffs learning, especially in the 
administrative departments. In order to succeed in implementing LSS in HEIs, superiors must always encourage the subordinates in continuous learning and exploring new knowledge.

\section{Project Selection and Prioritization}

According to Rathi et al. (2016), LSS is regarded as a project-driven strategy. Due to limited resources, and time, selection and prioritization need to be done in order to achieve effective LSS implementation as it is impossible to conduct every LSS strategy at one time. Mishandling of project selection and prioritization will end up the effort of LSS implementation being wasted (Pande, et al., 2000).

In terms of evaluating the project selection and prioritization, there are three criteria need to be fully examined (Anthony and Banuelas, 2002). These three criteria are based on the business benefit, organization impact and feasibility. Firstly, when implementing LSS, it must be on the project which bringing largest benefits to the organization. The benefits might refer to meeting customers' needs, improving company competencies in terms of financial, operational and etc. Organization impact, on the other hand, refers to the life-long learning of organization, such as new skills learned on customer or products as well as procedure. On top of that, the organization need to make sure that the project is feasible, which related to monetary (capital), complexity and proficiency obtainable.

In HEls, there are many operations such as recruitment, human resource system, financial projects, students learning, and etc. Due to the limited in resources, LSS project must be chosen based on its relevancy towards the aims of HEls. Periodically checking and monitoring of Project selected must be done to ensure the project is on the right track and in the right pace.

\section{Linking LSS to Human Resource (HR) rewards}

In management, HR rewards is considered the most direct way to enhance performance of employees. HR rewards can be monetary or non-monetary. Monetary reward refers to the financial compensation such as bonuses, allowances and etc. while non-monetary rewards refer to complement, recognition and acknowledgement from superior. In the research of Laureani and Anthony (2017), it is suggested that HR rewards is very vital in enhance employees' motivation and encourage them to work harder.

In terms of the inception of LSS, it is suggested that monetary rewards are much influential and important in HEls (Laureani and Anthony, 2017). Monetary rewards can used to stimulate the interest of employees in involvement to LSS project (Jayaraman and Teo, 2010). By giving the employees HR rewards, either monetary or non-monetary, they will be encouraged, and employees' motivation and engagement will be improved. This helps the HEls to achieve its LSS objectives and goals.

\section{Discussion and Conclusion}

Based on the findings, there are some opinions can be synthesized from the literature gathered from different authors.

Based on the prior literature, it can be seen that the implementation of continuous improvement tools is a must to every HEls in order to stay competitive under high pressure. 
Based on the five CSFs discussed in the literature review, it can be seen that the CSFs discussed are all vial to HEls to succeed in the LSS implementation. All these factors are aimed to encourage innovative ideas and improve the participation of employees in LSS projects.

It can be seen the role of management is very crucial in deciding these CSFs. Firstly, management commitment plays an important role which influence the other employees to participate in LSS activities. Without the initiatives by management team, the employees are not likely to be involved in LSS projects. Besides, management also important in terms of providing training and leading the cultural change in the HEls. In addition, the project selection and project prioritization needed to be carefully evaluated by the management to make the correct decision. Lastly, the HR rewards needed to be distributed by management to the employees to ensure they are interested and engage to the LSS projects. Other than management role, it is also need to emphasis on the role of employees as they serve the base of HEls which is considered as the fundamental of HEls. Without their support, the implementation of LSS would be wasted and most likely not successful even with the strong management support.

\section{Conclusion}

This paper aimed to evaluate the prior research on CSFs of LSS and its relevancy in HEls. The purpose of this paper is achieved, as all the CSFs are influential towards the implementation of LSS. Based on the literature of previous studies, it shows that all the CSFs is very relevant for HEls to achieve success in LSS implementation. Therefore, the CSFs in this paper will serve as a guideline for practitioners of LSS while adopting this approach. Despite these findings, it is essential for future researchers to explore more regarding to LSS in HEls as there are very rare research in this area of study. More research can be carried out to uncover the other CSFs or their effects on performance and other impact on the organization.

This study will be beneficial to both researchers and practitioners of LSS. Researchers can take this research as a fundamental for future research such as study each CSFs in details and their respective effects in enhancing the performance of an organization. The review of this study can serve as an overall opinion and understanding on LSS. On the other hand, practitioners or the stakeholders who wish to develop strategies pertaining to LSS can take the finding of this study as a guideline to better understand the CSFs in implementing the LSS, or current practitioners may adjust their strategies accordingly to fulfill the CSFs of the LSS. The insights can be used in the higher education institutions globally, and may be a fundamental in other education category, such as primary and secondary education.

\section{Acknowledgements}

This work was supported/funded by the Ministry of Higher Education under Fundamental Research Grant Scheme (FRGS/1/2019/SS03/UTM/02/8).

\section{References}

Aij, K. H., and Teunissen, M. (2017). Lean leadership attributes: A systematic review of the literature. Journal of Health Organization and Management, 31(7/8), pp. 713-729.

Aij, K. H., Simons, F. E., Widdershoven, G. A. M., and Visse, M. (2013). Experiences of leaders in the implementation of Lean in a teaching hospital- Barriers and facilitators in clinical practices: A qualitative study. BMJ Open, 3(10). 
Ali, N. N. K., Choong, C. W. and Jayaraman, K. (2016). Critical success factors of Lean Six Sigma practices on business performance in Malaysia. International Journal of Productivity and Quality Management, 17(4), pp. 456-473.

Anthony, J., and Banuelas, R. (2002). Key ingredients for the effective implementation of Six Sigma program. Measuring Business Excellence, 6(4), pp. 20-27.

Anthony, J., Escamilla, J. L., and Caine, P. (2003). Lean Sigma. Manufacturing Engineer, 82(2), 40-42.

Antony, J. (2014). Readiness factors for the Lean Six Sigma journey in the higher education sector. International Journal of Productivity and Performance Management. 63(2): 257-264.

Antony, J., Krishan, N., Cullen, D., \& Kumar, M. (2012). Lean Six Sigma for higher education institutions (HEls): challenges, barriers, success factors, tools/techniques. International Journal of Productivity and Performance Management. 61(8): 940-948.

Bhasin, S., and Burcher, P. (2006). Lean Viewed as a Philosophy. Journal of Manufacturing Technology, 35(1), 56-72.

Bisgaard, S., Hoerl, R. W., and Snee, R. D. (2002). Improving business processes with Six Sigma. Annual Quality Congress Proceedings, 701-704.

Brun, A. (2011). Critical success factors of Six Sigma implementations in Italian companies. International Journal of Production Economics, 131(1), pp. 158-164.

El-Homsi, A., \& Slutsky, J., (2010). Corporate sigma: optimizing the health of your company with systems thinking. New York. Productivity Press. Taylor \& Francis Group.

Furterer, S., and Elshennawy, A. K. (2005). Implementation of TQM \& Lean Six Sigma tools in local government: A framework \& a case study. Total Quality Management \& Business Excellence, 16(10), 1179-1191.

Geert, H., Gert, J. H., and Michael, M. (2010). Cultures and organizations: Software of the mind, $3^{\text {rd }}$ ed., New York: McGraw-Hill.

George, M. L. (2003) Lean Six Sigma for service: How to use Lean speed and Six Sigma quality to improve services and transactions. New York: McGraw-Hill.

Godfrey, A. B. (2005). Successes, failures, and concerns. ASQ Six Sigma Forum Magazine, 4(3), pp. 6-8.

Goodridge, D., Westhorp, G., Rotter, T., Dobson, R., and Bath, B. (2015). Lean and leadership practices: Development of an initial realist program theory. BMC Health Service Research, 15(1), pp. 1-15.

Jayaraman, K., and Teo, L. K. (2010). A conceptual framework for critical success factors of Lean Six Sigma: Implementation on the performance of electronic manufacturing service industry. International Journal of Lean Six Sigma, 1(3), pp. 191-215.

Jing, G. G. (2009). A Lean Six Sigma breakthrough. Quality Progress, 42(5), 24-31.

Kanji, G. K., Malek, A., and Tambi, B. A. (1999). Total quality management in UK higher education institutions. Total Quality Management, 10(1), 129-153.

Keim, E. M. (2011). Shortcut don't get you there faster. ASQ Six Sigma Forum Magazine, 10(3), pp. 31-37.

Kotter, J. P., and Heskett, J. L. (1992). Corporate culture and performance. Free Press.

Kulach, P. S. (2013). A quantitative correlational analysis between six sigma training and compensation of six sigma practitioners. University of Pheonix.

Kwak, Y. H., and Anbari, F. T. (2006). Benefits, obstacles and future of Six Sigma approach. Technovation, 26(6), pp. 708-715. 
Laureani, A., and Anthony, J. (2017). Leadership characteristic for Lean Six Sigma. Total Quality Management and Business Excellence, 28(3/4), pp. 405-426.

Maijala, R., Eloranta, S., Reunanen, T., and Ikonen, T. S. (2018). Successful implementation of Lean as a managerial principle in healthcare: A conceptual analysis from systematic literature review. International Journal of Technology Assessment in Healthcare, 34(2), pp. 134-146.

Mehrjerdi, Y. Z. (2011) Six sigma: methodology, tools and its future. Assembly Automation, 31(1), 79-88.

Melovic, B., Mitrovic, S., Zhuravlev, A., and Braila, N. (2016). The role of the concept of Lean management in modern business, MATEC Web of Conferences, 86, 1-4.

Mergen, E., Grant, D. and Widrick, S. M. (2000). Quality management applied to higher education. Total Quality Management, 11(3), 345-352.

Ministry of Education. (2013), Malaysia Education Blueprint 2015-2025, Ministry of Education, Putrajaya.

Pande, P., and Holpp, L. (2002). What is Six Sigma. New York: McGraw-Hill.

Pepper, M. P., \& Spedding, T. A. (2010). The evolution of lean six sigma. International Journal of Quality and Reliability Management. 27(2): 138-155.

Pettersen, J., (2009). Defining Lean Production: Some Conceptual and Practical Issues. The TQM Journal, 21(2), 127-142.

Poksinska, B., Swartling, D., and Drotz, E. (2013). The daily works of Lean leaders- lessons from manufacturing and healthcare. Total Quality Management and Business Excellence, 24(7/8), pp. 886-898.

Quinn, A., Lemay, G., Larsen, P., and Johnson, D. (2009). Service quality in higher education. Total Quality Management, 20(2), pp. 139-152.

Rathi, R., Khanduja, D., and Sharma, S. (2016). A fuzzy MADM approach for project selection: A Six Sigma case study. Decision Science Letters, 5(2), pp. 255-268.

Rodriguez, J., and Walters, K. (2017). The importance of training and development in employee performance and evaluation. World Wide Journal of Multidisciplinary Research and Development, 3(10), 206-212.

Singh, D., and Singh, G. (2020). Critical success factors for Six Sigma implementation in India SMEs: An evaluation using AHP. Measuring Business Excellence.

Snee, R. D. (2010). Lean Six Sigma- Getting better all the time. International Journal of Lean Six Sigma, 1(1), 9-29.

Taj, S., and Berro, L. (2005). Application of constrained management and lean manufacturing in developing best practices for productivity improvement in auto- assembly plant. International Journal of Productivity and Performance Management. 55(3/4), 332-45.

Vijaya, S. M. (2016). Lean Six Sigma in higher education institutions. International Journal of Quality and Service Sciences. 8(2): 159-178. 